\title{
EXPLOITING VOLUNTEERED GEOGRAPHIC INFORMATION TO EASE LAND USE MAPPING OF AN URBAN LANDSCAPE
}

\author{
J. Jokar Arsanjani ${ }^{\mathrm{a}}$, M. Helbich ${ }^{\mathrm{b}}$, M. Bakillah ${ }^{\mathrm{c}}$
}

\author{
${ }^{a}$ University of Heidelberg, GIScience, Institute of Geography, 69120 Heidelberg, Germany - jokar.arsanjani@geog.uni- \\ heidelberg.de \\ ${ }^{\mathrm{b}}$ University of Heidelberg, GIScience, Institute of Geography, 69120 Heidelberg, Germany - marco.helbich@geog.uni- \\ heidelberg.de \\ ${ }^{c}$ University of Heidelberg, GIScience, Institute of Geography, 69120 Heidelberg, Germany - \\ mohamed.bakillah@geog.uni-heidelberg.de
}

KEY WORDS: land use, urban landscape, volunteered geographic information, OpenStreetMap, supervised classification

\begin{abstract}
:
Remote sensing techniques have eased land use/cover mapping substantially by observing the earth remotely through diminishing field surveying and in-site data collection. However, field measurement is still required to identify training sites for defining the existing land use classes, which requires visiting the study area. This paper is intended to utilize volunteered geographic information (VGI) contributions to the OpenStreetMap (OSM) project as an alternative data source instead of gathering training sites through insite visits and to evaluate how accurate land use patterns can be mapped. High resolution imagery of RapidEye with 5 meter spatial resolution is selected to derive land use patterns of Koblenz, Germany through a maximum likelihood classification technique. The achieved land use map is compared with the Global Monitoring for Environment and Security Urban Atlas (GMESUA) and a Kappa Index of $89 \%$ is achieved. The outcomes prove that VGI can be integrated within remote sensing processes to facilitate the process of earth observation and monitoring.
\end{abstract}

\section{INTRODUCTION}

\subsection{Land Use Mapping}

Land cover/use maps play a key role in monitoring environmental phenomena, ecological studies, urban management, etc. Land cover/use maps represent physical and biological cover on the surface and human activities such as agriculture, forestry, and building construction that alter land surface, respectively (de Sherbinin 2002; Ellis 2007; Jokar Arsanjani et al., 2013).

Ever since remote sensing emerged in earth observation, this multidisciplinary and interdisciplinary field has been evolving every day (amongst Anderson 1976). Therefore, less in-field measurements and on-site checks are required, however within applying the remote sensing techniques, researchers are opt to either visit the study area and collect some samples or be given up-to-date information of study area. This implies that in-field checks are still a crucial stage, which keeps researchers dependent on field visits (Saadat et al., 2011). This is not an exception in the case of land use mapping as mappers have to check the resulting maps with the reality through evaluating them with some taken sample points of the actual situation on the earth whilst the land mapper might not be necessarily familiar with the study area. Therefore, either a non-familiar person with land features must be asked to help or the land mapper is ought to spend a while to get familiar with the area. Either way the outputs are prone to land use/cover misclassifications, which results in propagation of uncertainty through modelling and conversions (Pontius et al., 2004).
On the other hand, due to the development of Web 2.0 technologies, a number of data repositories and web map services (WMSs: Esri's Basemaps, Google Earth, Bing Maps as such) are released and available via application programming interfaces (APIs) to enable people to see the latest aerial image of the earth. However, collaborative mapping projects (CMPs, Rouse et al., 2007) also give the opportunity of mapping geographical objects in the hand of interested people by overlaying high-resolution image libraries. So far, a number of CMPs, namely Geo-wiki and OSM, have been launched to collect geolocated information from volunteers (Turner, 2006), which is termed VGI (Goodchild, 2007). Among active CMPs, OSM has been a legendary collaborative project due to attracting high amount of public attention and contribution. Nearly 1,120,000 users until April 2013 have been contributed (OpenStreetMap 2012). Three main issues concerning the OSM contributions must be mentioned: first, some data are new and have never been collected before in the proprietary databases (Neis and Zipf, 2012; Corcoran \& Mooney, 2012). Second, OSM contributions with high positional accuracy in comparison with the commercial dataset have been achieved (Helbich et al. 2012). Therefore, it is assumed that VGI data from the crowd have the potential to be an alternative source for collecting training samples as well as sample points instead of field measurements. Hence, this paper aims at exploiting the freely distributed geodata to the VGI services specifically OSM in order to expedite and facilitate the process of land use/cover mapping through remote sensing in two ways, a) providing training samples and b) accessing the accuracy of classification's outputs. In other words, the main objective of

\footnotetext{
* Corresponding author.
} 
this investigation is to find out how good an urban landscape can be mapped through replacing traditional in-field training sites with VGI-based training sites.

The paper is structured as follows: an overview of the utilized datasets and the chosen study site is given within the next section. Section 3 presents the applied methods and achieved results. Section 4 presents a discussion on the attained outcomes and concludes this investigation.

\section{MATERIALS}

\subsection{Study area}

For this investigation, the city of Koblenz, Germany, is selected. The reasons for selecting this city are that: a) this city has attracted a significant amount of contributions, which is evident in OSMatrix (Roick et al., 2011), b) the selected area of interest (AOI) covers a diverse landscape so that several land features are detected (see http://www.eea.europa.eu/data-andmaps/data/urban-atlas), c) the Global Monitoring for Environment and Security Urban Atlas (GMESUA) data for the AOI has already been generated for the accuracy assessment process. Therefore, the selected area (Figure 1) is representative and typical in order to test the above-mentioned assumptions.

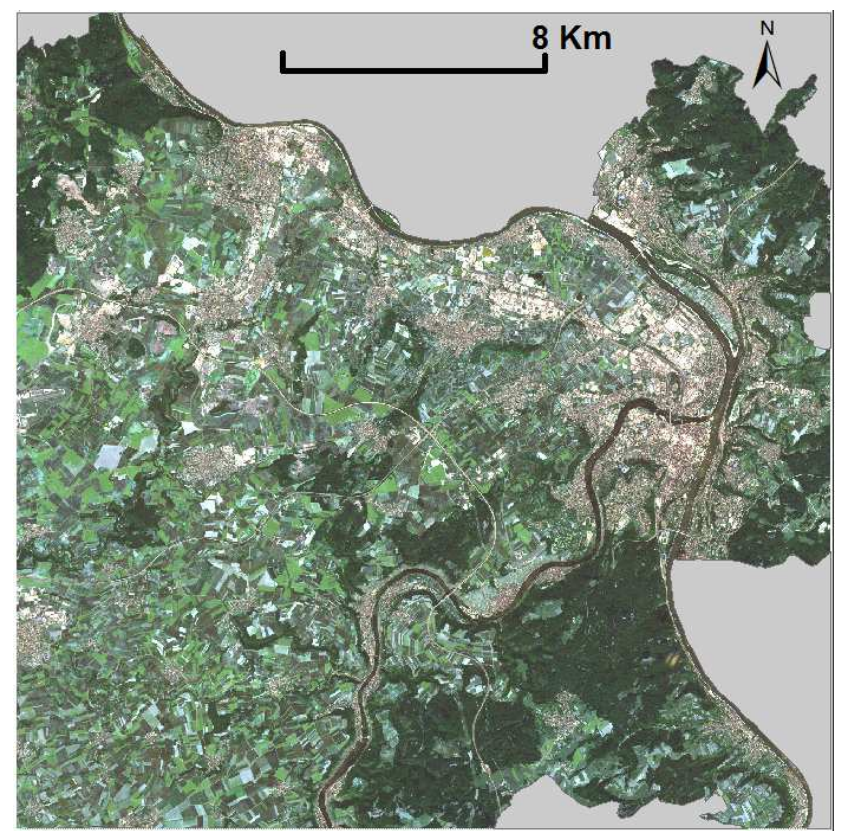

Figure 1: The geographical extent of study area

\subsection{Datasets and Data Processing}

\subsubsection{Remote Sensing Data}

The RapidEye mission consisting five satellites was launched in April 2010 aiming at high-resolution mapping of urban landscapes (Tapsall et al., 2010). The RapidEye sensor has a multispectral imager with a spatial resolution of $6.25 \mathrm{~m}$ and stores data in five spectral bands from visible to near-infrared. The delivered image is level 3A (Ortho product), which is radiometrically and geometrically corrected based on the digital terrain elevation data level-1 from Shuttle Radar Terrain Mission (SRTM) (RapidEye, 2010; Vuolo et al., 2010).

\subsubsection{OpenStreetMap Dataset}

The OSM project structures contributions from volunteers into several layers e.g., roads, POIs, buildings, waterways, natural and land use features (OpenStreetMap 2012). The OSM data of the AOI was downloaded from the official data provider Geofabrik in November 2012.

\subsubsection{Global Monitoring for Environment and Security Urban Atlas (GMESUA) Dataset}

The GMESUA provides pan-European comparable land use patterns for large urban zones with populations of more than 100,000. It has been produced for the mapping urban landscapes and contains information that can be derived chiefly from Earth Observation (EO) data supported by other reference data, such as commercial-off-the-shelf (COTS) navigation data and topographic maps (European Union, 2011). In addition to high-resolution satellite images, supplementary data are used to improve the accuracy of classification such as: a) COTS navigation data; b) Google Earth; c) local city maps for certain classes; d) local zoning data; and e) field checks (European Environment Agency, 2010). Currently, this dataset covers 305 urban regions within Europe. Recently, Hagenauer and Helbich (2012) have used GMESUA and OSM to delimitate urban areas. Within the study area twenty different land use categories are distinguished. The GMESUA data of Koblenz was also downloaded from the European Environment Agency (EEA) website, which represents land use patterns of 2010 .

\section{METHODS AND RESULTS}

\subsubsection{Classification technique}

In order to classify the remote sensing image (RapidEye), a supervised classification approach using the maximum likelihood classification (MLC) algorithm was applied. MLC is a widely-used parametric classifier. To select the most optimal training sites (spectral features), the contributions to OSM i.e., natural features, land use patterns, roads, buildings, POIs, and waterways were harmonized with the GMESUA classes and then imported into the classification process. The classification scheme was based on the European Union standard applied for the GMESUA dataset (see European Union, 2011). This made the resultant land use map compatible with the GMESUA for accuracy assessment. However, the training sites were checked once again with the Google Earth interface and outliers were erased from the database. So, VGI was implemented as an alternative source of information instead of field measurements. The resultant classified land use patterns and GMESUA map are presented in Figure 2 and 3, respectively.

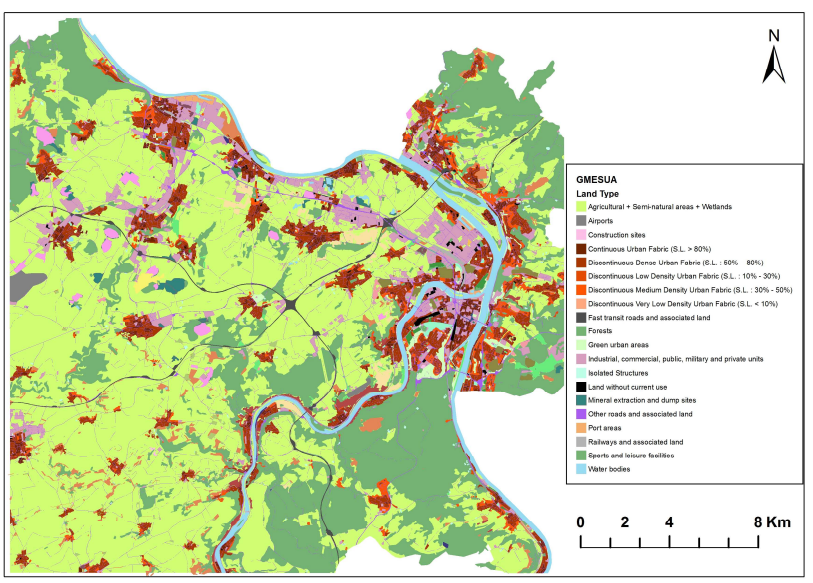

Figure 2: The achieved land use map of Koblenz 


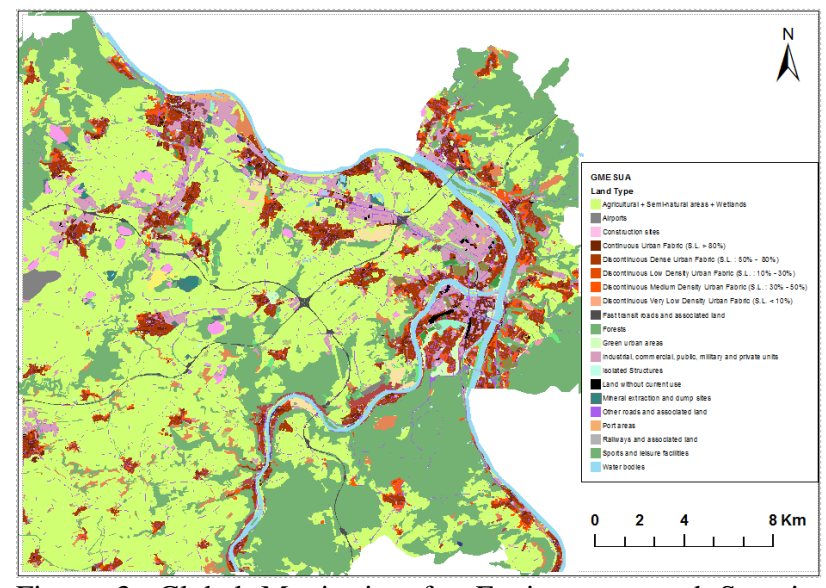

Figure 3: Global Monitoring for Environment and Security Urban Atlas (GMESUA) land use map (European Union, 2011)

\subsubsection{Accuracy assessment}

The accuracy assessment of the classification tasks was performed through comparing the resultant land use map and the GMESUA map. A Kappa index analysis was applied to measure the degree of match between the two datasets, which statistically explains how well two thematic datasets match. The Kappa index varies between 0 and $100 \%$, where $0 \%$ indicates that the level of agreement is equal to the agreement due to chance and $100 \%$ indicates perfect agreement. A Kappa index of $89 \%$ was achieved.

\section{DISCUSSIONS AND CONCLUSIONS}

Remote sensing techniques have been broadly used to map environmental phenomena and terrestrial features, which revolutionized the environment-related disciplines. They have extensively decreased the time and costs to be spent on monitoring and managing the earth. On the other hand, the recent development of Web 2.0 technologies has made a new revolution in acquiring a new source for providing geoinformation, which is called VGI. VGI platforms have been providing valuable geodata as a new potential source of collecting geoinformation. In this study, volunteers' contributions to a well-known collaborative mapping project, i.e. OSM were collected and the required training sites for the classification process were determined from it to find out how accurate the land use patterns can be mapped. The GMESUA dataset was used to assess the resultant land use map. The obtained Kappa index at $89 \%$ proves that using VGI as a data source for introducing training sites to the remote sensing processes is appropriate. However, the quality of VGI is heterogeneous and location-dependant, therefore it is recommended to check the amount of contributions and then to use it for such purposes. It is also recommended to consider other VGI data e.g., Flickr photos to support the accuracy of classification.

\section{REFERENCES}

Anderson, J. R. (1976). A land use and land cover classification system for use with remote sensor data (Vol. 964). US Government Printing Office.
Corcoran, P., \& Mooney, P. (2012: in press). Characterising the Metric and Topological Evolution of OpenStreetMap Network Representations. European Physical Journal, Special Topics.

De Sherbinin, A. (2002). A CIESIN Thematic Guide to Land Land-Use and Land Land-Cover Change (LUCC). Center for International Earth Science Information Network (CIESIN) Columbia University Palisades, NY, USA.

Ellis E., (2007). "Land-use and land-cover change" In: Encyclopedia of Earth. Eds. Pontius R., Cleveland C.J. Available at http://www.eoearth.org/article/Land-use_and_landcover_change.

European Union, (2011). Mapping Guide for a European Urban Atlas. Available at http://www.eea.europa.eu/data-andmaps/data/urban-atlas.

Goodchild, M. F. (2007). Citizens as sensors: The world of volunteered geography. GeoJournal, 69, pp 211-221.

Hagenauer, J., \& Helbich, M, (2012), Mining Urban Land-Use Patterns from Volunteered Geographic Information by means of Genetic Algorithms and Artificial Neural Networks. International Journal of Geographical Information Science, 26(6), 963-982.

Helbich, M., Amelunxen, C., \& Neis, P. (2012). Comparative Spatial Analysis of Positional Accuracy of OpenStreetMap and Proprietary Geodata. International GI_Forum. Salzburg, Austria.

Jokar Arsanjani, J., Helbich, M., Kainz, W., \& Bloorani, A. D. (2013). Integration of logistic regression, Markov chain and cellular automata models to simulate urban expansion. International Journal of Applied Earth Observations and Geoinformation, Vol 21, pp. 265-275.

Neis, P., \& Zipf, A., (2012). Analyzing the Contributor Activity of a Volunteered Geographic Information Project - The Case of OpenStreetMap, ISPRS International Journal of GeoInformation.

OpenStreetMap, (2012). OpenStreetMap wikipage on Quality Assurance retrieved at

http://wiki.openstreetmap.org/wiki/Quality_Assurance.

Pontius, Jr, R. G., Huffaker, D., \& Denman, K. (2004). Useful techniques of validation for spatially explicit land-change models. Ecological Modelling, 179(4), 445-461.

RapidEye, (2010). RapidEye Standard Image Product Specification, Version 3.0, Germany, www.rapideye.de.

Roick, O., Hagenauer, J., \& Zipf, A. (2011). OSMatrix - Gridbased Analysis and Visualization of OpenStreetMap. In proceedings of the State of the Map EU 2011. Vienna, Austria.

Rouse, L. J., Bergeron, S. J., \& Harris, T. M. (2007). Participating in the Geospatial Web: Collaborative Mapping, Social Networks and Participatory GIS. In A. Scharl \& K. Tochtermann (Eds.), The Geospatial Web (pp. 153-158). Springer London.

Saadat, H., Adamowski, J., Bonnell, R., Sharifi, F., Namdar, M., \& Ale-Ebrahim, S. (2011). Land use and land cover 
International Archives of the Photogrammetry, Remote Sensing and Spatial Information Sciences,

Volume XL-4/W1, 29th Urban Data Management Symposium, 29 - 31 May, 2013, London, United Kingdom

classification over a large area in Iran based on single date analysis of satellite imagery. ISPRS Journal of Photogrammetry and Remote Sensing, 66(5), 608-619.

Tapsall, B., Milenov, P., \& Tasdemir, K. (2010). Analysis of RapidEye imagery for annual land cover mapping as an aid to European Union (EU) Common Agricultural Policy. In ISPRS TC VII Symposium, Vol. 100, pp. 568-573.

Vuolo, F., Atzberger, C., Richter, K., Urso, G.D., Dash, J., (2010). Retrieval of biophysical vegetation products from RapidEye imagery. In: Wagner, W., Szekely, B. (Eds.), ISPRS TC VII Symposium-100 years ISPRS. Vienna, Austria.

\section{ACKNOWLEDGEMENTS}

Jamal Jokar Arsanjani was funded by the Alexander von Humboldt foundation. 
International Archives of the Photogrammetry, Remote Sensing and Spatial Information Sciences,

Volume XL-4/W1, 29th Urban Data Management Symposium, 29 - 31 May, 2013, London, United Kingdom 